\title{
Cone beam computed tomography in endodontics: the missing link?
}

\author{
Eyal Rosen ${ }^{*}$ and Igor Tsesis
}

\begin{abstract}
Cone beam computed tomography $(\mathrm{CBCT})$ has become a popular diagnostic method in endodontics. However, recently published data provides a glance into possible missing links regarding the efficacy of CBCT and its use to support the endodontic clinical decision-making process.
\end{abstract}

\section{Editorial}

The integration of cone beam computed tomography $(\mathrm{CBCT})$ imaging in the daily endodontic practice has become popular. Many studies (Ustun et al. 2016; Gambarini et al. 2018; Perez-Heredia et al. 2017; Wanderley et al. 2018; Dinsbach 2018), including several position statements (AAE and AAOMR Joint Position Statement 2015; AAE, AAOMR 2010), have been published in recent years, advocating for the daily use of CBCT for many endodontic purposes such as for the diagnosis of periapical pathologies (Leonardi Dutra et al. 2016). In most of these publications, it is generally stated that, due to its excessive radiation dose compared to intraoral periapical radiography (PR) (Patel et al. 2015), the use of CBCT should be precautious and should be justified for each individual patient. However, usually, these precautionary measures are only vaguely defined, and structured case selection criteria are only rarely provided (Rosen et al. 2017). Furthermore, in most of these studies, the required "better safe than sorry" modern preventive approach is not implemented. This approach advocates measures to prevent the potential harmful effect of CBCT even when it is not certain to occur (Rosen et al. 2017; Rosen et al. 2015; Science for Environment Policy 2017). This approach is not well applied in endodontic CBCT, maybe due to the (mis-) assumption that the immediate benefit from the use of $\mathrm{CBCT}$ is significant (AAE, AAOMR 2010; Rosen et al. 2015; Berman and Hartwell 2006), and to the fact that the

\footnotetext{
* Correspondence: dr.eyalrosen@gmail.com

Department of Endodontology, Maurice and Gabriela Goldschleger School of Dental Medicine, Tel Aviv University, Tel Aviv, Israel
}

harmful effects of the CBCT radiation exposure may not be evident until years after the actual exposure (Rosen et al. 2017; Science for Environment Policy 2017; EUROPEAN-COMMISSION 2012; Ludlow et al. 2015; Pauwels et al. 2014; Pearce et al. 2012; Wu et al. 2015; Yeh and Chen 2018; Kamburoğlu et al. 2017).

Another issue is the power of the sheer number of publications on $\mathrm{CBCT}$ in endodontics, which potentially affects the general perception of the extent and value of CBCT use in endodontics. A current electronic search by PubMed search engine for articles assessing the use of CBCT in endodontics, identical to the search done by Rosen et al. in 2015 (Rosen et al. 2015), found a staggering number of 1140 articles (PubMed search engine n.d.), many of which advocate the use of CBCT in endodontics. This overwhelming number of published articles, together with a lack of agreement on a rational case selection protocol for the use of CBCT in endodontics, may give the (wrong) impression that the use of $\mathrm{CBCT}$ in endodontics is scientifically well established, safe, and justified for the benefit of the common endodontic patient.

However, several systematic reviews published in recent years assessed the ultimate benefit of endodontic CBCT by using a diagnostic efficacy hierarchical model (Rosen et al. 2015; EUROPEAN-COMMISSION 2012; Kruse et al. 2015). They all concluded that the expected ultimate benefit of $\mathrm{CBCT}$ to the endodontic patient is yet unclear, and that the currently available literature is mainly limited to the assessment of the CBCT's technical and accuracy efficacies, rather than the assessment of its ultimate benefit to clinical decision making and to treatment outcomes (Rosen et al. 2015; EUROPEAN-COMMISSION 2012; Kruse et al. 2015). These conclusions are in accordance with other 
recently published articles in other disciplines of dentistry (EUROPEAN-COMMISSION 2012; Kim et al. 2011; Matzen and Wenzel 2015; Nikolic-Jakoba et al. 2016; Pittayapat et al. 2014). The fact that the expected ultimate benefit of $\mathrm{CBCT}$ to the endodontic patient is yet unclear does not necessarily mean that $\mathrm{CBCT}$ is not effective. It just means that there are substantial missing links regarding its true efficacy and benefits to the endodontic patient.

Recently, two publications provided a glance into some of these missing links. In the first publication, Kruse et al. (2018) assessed how additional information acquired from $\mathrm{CBCT}$ affects the periapical diagnosis and treatment planning that was originally based on clinical examination and PR. Three observers initially assessed the PR of patients who were followed up after surgical endodontic retreatment and provided an initial diagnosis and treatment plan. Later, the CBCTs were assessed and a second "corrected" diagnosis and treatment plan was provided. Eventually, out of 74 teeth (in 66 patients), the radiographic diagnosis was changed as a result of the CBCT evaluation in 38 cases (51.4\%). The treatment plan was changed for 18 teeth (24.3\%), and for 14 teeth (18.9\%), the change was from no treatment/further observation to a more invasive treatment plan (reoperation or extraction). The authors concluded that the use of CBCT for follow-up after surgical endodontic treatment led to more cases diagnosed with apical periodontitis and consequently to the recommendation of a more invasive treatment plan (Kruse et al. 2018).

A superficial look on these results may lead to the (wrong) conclusion that CBCT is more effective in the diagnosis of periapical pathologies following surgical endodontic treatment and that its use will lead to a more suitable treatment plan. This common mistake in the interpretation of the results of clinical articles comparing the diagnostic efficacy of CBCT to $\mathrm{PR}$ is due to a lack of an appropriate reference standard, defined as "the best available method for establishing the presence or absence of the target condition" (Bossuyt and Leeflang 2008). In endodontics, the required reference standard in such clinical studies is an histological evaluation (Leonardi Dutra et al. 2016; Petersson et al. 2012). Unfortunately, in many other comparable clinical publications in endodontics (Leonardi Dutra et al. 2016; Patel et al. 2012; Uraba et al. 2016), such reference standards were not used, which jeopardizes the validity of their results. In fact, a comprehensive systematic review of the literature (Leonardi Dutra et al. 2016) that assessed the diagnostic accuracy of PR and $\mathrm{CBCT}$ in the discrimination of apical periodontitis from no lesion initially identified 665 potentially relevant articles. However eventually, only 9 articles fulfilled the inclusion criteria including a reference standard defined as a histologic examination for actual (in vivo) or induced artificial (in vitro) apical periodontitis. Additional 13 articles were excluded since the required reference standard was not used (Leonardi Dutra et al. 2016).

Although in the current article (Kruse et al. 2018), a reference standard was not used, the authors did not overlook this limitation and stated that "evidence is still missing on the true histological nature of periapical radiolucencies found using CBCT for follow-up after surgical endodontic treatment", and that "future studies should be designed to investigate this and hence serve as a basis of periapical healing assessment criteria for CBCT evaluation after surgical endodontic treatment" (Kruse et al. 2018).

Furthermore, the same authors recently published another article (Kruse et al. 2017) providing the other side of the coin to this missing link: the aim of this study was to assess the diagnostic validity of PR and CBCT in surgical endodontic treatment cases that were re-operated. The uniqueness of this article is the histology of the periapical tissues that was taken during the re-surgery as (an appropriate) reference standard for the radiographic examinations. Records of patients after surgical endodontic treatment were screened, of which 108 patients (119 teeth) were recalled for clinical and radiographic examination (PR and $\mathrm{CBCT}$ ). Seventy-four patients (83 teeth) were examined. Three observers assessed the periapical and $\mathrm{CBCT}$ radiographs, and re-surgery was offered to non-healed teeth. All 19 re-operated teeth that were included in the histological evaluation were assessed as non-healed in CBCT, while 11 of these were assessed as successfully healed in the PR. During re-surgery, biopsy was performed and histopathology verified whether or not periapical inflammation was present. Importantly, out of 19 biopsies, $42 \%$ (8 teeth) were without periapical inflammation histologically, $16 \%$ (3 teeth) had mild inflammation, and 42\% (8 teeth) had moderate to intense inflammation. A correct diagnosis was obtained in 58\% with CBCT (true positives) and $63 \%$ with PR (true positives+true negatives). Based on these results, the authors (correctly) concluded that of the re-operated teeth, $42 \%$ had no periapical inflammatory lesion, and therefore no benefit from re-surgery, and that not all lesions observed in CBCT represented true periapical inflammatory lesions (Kruse et al. 2017). Although limited in its extent, the results of this unique article provide an important insight into a significant missing link in the use of $\mathrm{CBCT}$ in endodontics.

Furthermore, these two articles (Kruse et al. 2018; Kruse et al. 2017) are actually the two sides of the same coin: on one side of the coin, the use of CBCT for follow-up after surgical endodontic treatment may lead to more cases diagnosed with apical periodontitis and to an ensuing recommendation of an invasive treatment 
plan (Kruse et al. 2018). On the other side of the coin (Kruse et al. 2017), many of the "lesions" observed in CBCT do not represent true periapical inflammatory lesions. Thus, the overall results of these two studies (Kruse et al. 2018; Kruse et al. 2017) indicate a significant missing link and concerns regarding the use of $\mathrm{CBCT}$ for the diagnosis of periapical lesions and for clinical decision making: CBCT use may lead to overdiagnosis and over-treatment (Moynihan et al. 2014). Thus, there is great need for further studies of high-quality and appropriate study design to assess the true efficacies and risks of CBCT, and for the time being, the use of $\mathrm{CBCT}$ for endodontic decision making should be more carefully considered.

\section{Authors' contributions}

The authors shared equal contribution. Both authors read and approved the final manuscript.

\section{Ethics approval and consent to participate}

Not Applicable.

\section{Consent for publication}

Not Applicable.

\section{Competing interests}

The authors declare that they have no competing interests.

\section{Publisher's Note}

Springer Nature remains neutral with regard to jurisdictional claims in published maps and institutional affiliations.

Received: 30 August 2018 Accepted: 5 September 2018

Published online: 15 September 2018

\section{References}

$A A E, A A O M R$, editors. AAE and AAOMR joint position statement-use of conebeam-computed tomography in endodontics 2010.

AAE and AAOMR Joint Position Statement: Use of cone beam computed tomography in endodontics; 2015 Update 2015.

Berman LH, Hartwell GR. Diagnosis. In: Cohen S, Hargreaves KM, editors. Pathways of the pulp, 9 ed. 9th ed. St. Louis: MOSBY; 2006. p. 2-39.

Bossuyt PM, Leeflang MM. Chapter 6: developing criteria for including studies. Cochrane Handbook for Systematic Reviews of Diagnostic Test Accuracy 2008

Dinsbach N. Benefits of preoperative cone beam computed tomography for root canal therapy in posterior teeth. Gen Dent. 2018;66(1):6-8.

EUROPEAN-COMMISSION, editor Radiation protection No 172 Cone beam CT for dental and maxillofacial radiology (Evidence-based guidelines). the SEDENTEXCT project; 2012; Luxembourg.

Gambarini G, Piasecki L, Miccoli G, Gaimari G, Nardo DD, Testarelli L. Cone-beam computed tomography in the assessment of periapical lesions in endodontically treated teeth. Eur J Dent. 2018;12(1):136-43.

Kamburoğlu K, Tsesis I, Rosen. What do we (do not) know about the use of cone beam computed tomography in endodontics? A thematic series with a call for scientific evidence. E Evid-Based Endod. 2017;2:3 https://doi.org/10.1186/ s41121-017-0008-z.

Kim IH, Patel MJ, Hirt SL, Kantor ML. Clinical research and diagnostic efficacy studies in the oral and maxillofacial radiology literature: 1996-2005. Dentomaxillofac Radiol. 2011;40(5):274-81.

Kruse C, Spin-Neto R, Reibel J, Wenzel A, Kirkevang LL. Diagnostic validity of periapical radiography and $\mathrm{CBCT}$ for assessing periapical lesions that persist after endodontic surgery. Dentomaxillofac Radiol. 2017;46(7):20170210.

Kruse C, Spin-Neto R, Wenzel A, Kirkevang LL. Cone beam computed tomography and periapical lesions: a systematic review analysing studies on diagnostic efficacy by a hierarchical model. Int Endod J. 2015;48(9):815-28.
Kruse C, Spin-Neto R, Wenzel A, Vaeth M, Kirkevang LL. Impact of cone beam computed tomography on periapical assessment and treatment planning five to eleven years after surgical endodontic retreatment. Int Endod J. 2018;51(7):729-37.

Leonardi Dutra K, Haas L, Porporatti AL, Flores-Mir C, Nascimento Santos J, Mezzomo LA, et al. Diagnostic accuracy of cone-beam computed tomography and conventional radiography on apical periodontitis: a systematic review and Meta-analysis. J Endod. 2016;42(3):356-64.

Ludlow JB, Timothy R, Walker C, Hunter R, Benavides E, Samuelson DB, et al. Effective dose of dental CBCT-a meta analysis of published data and additional data for nine CBCT units. Dentomaxillofac Radiol. 2015;44(1):20140197.

Matzen $\mathrm{LH}$, Wenzel A. Efficacy of cone beam computed tomography for assessment of impacted mandibular third molars: a review based on a hierarchical model of evidence. Dentomaxillofac Radiol. 2015;44(1):20140189.

Moynihan R, Henry D, Moons KG. Using evidence to combat overdiagnosis and overtreatment: evaluating treatments, tests, and disease definitions in the time of too much. PLoS Med. 2014;11(7):e1001655.

Nikolic-Jakoba N, Spin-Neto R, Wenzel A. Cone-beam computed tomography for detection of intrabony and furcation defects: a systematic review based on a hierarchical model for diagnostic efficacy. J Periodontol. 2016;87(6):630-44.

Patel S, Durack C, Abella F, Shemesh H, Roig M, Lemberg K. Cone beam computed tomography in endodontics- a review. Int Endod J. 2015;48(1)3-15. https://doi. org/10.1111/iej.12270.

Patel S, Wilson R, Dawood A, Mannocci F. The detection of periapical pathosis using periapical radiography and cone beam computed tomography - part 1: pre-operative status. Int Endod J. 2012;45(8):702-10.

Pauwels R, Cockmartin L, Ivanauskaite D, Urboniene A, Gavala S, Donta C, et al. Estimating cancer risk from dental cone-beam CT exposures based on skin dosimetry. Phys Med Biol. 2014;59(14):3877-91.

Pearce MS, Salotti JA, Little MP, McHugh K, Lee C, Kim KP, et al. Radiation exposure from CT scans in childhood and subsequent risk of leukaemia and brain tumours: a retrospective cohort study. Lancet. 2012;380(9840):499-505.

Perez-Heredia M, Ferrer-Luque CM, Bravo M, Castelo-Baz P, Ruiz-Pinon M, Baca P. Cone-beam computed tomographic study of root anatomy and canal configuration of molars in a Spanish population. J Endod. 2017;43(9):1511-6.

Petersson A, Axelsson S, Davidson T, Frisk F, Hakeberg M, Kvist T, et al. Radiological diagnosis of periapical bone tissue lesions in endodontics: a systematic review. Int Endod J. 2012:45(9):783-801.

Pittayapat P, Limchaichana-Bolstad N, Willems G, Jacobs R. Three-dimensional cephalometric analysis in orthodontics: a systematic review. Orthod Craniofac Res. 2014;17(2):69-91.

PubMed search engine (http://www.ncbi.n/m.nih.gov/sites/pubmed), Accessed 15 Aug 2018 with the following keyword: ((endodontic) OR root canal) AND ((cbct) OR cone beam) (n.d.).

Rosen E, Allareddy V, Tsesis I. Case selection for the use of cone beam computed tomography in dentistry based on diagnostic efficacy and risk assessment. In: Rosen E, Nemcovsky CE, Tsesis I, editors. Evidence-based decision making in dentistry: multidisciplinary management of the natural dentition. Switzerland: Springer International Publishing; 2017. p. 97-108.

Rosen E, Taschieri S, Del-Fabbro M, Beitlitum I, Tsesis I. The diagnostic efficacy of cone-beam computed tomography in endodontics: a systematic review and analysis by a hierarchical model of efficacy. Accepted for publication, JOE 2015.

Science for Environment Policy (2017) The precautionary Priniple: decision making under uncertainty. Future brief 18. Produced for the European Commission DG Environment by the Science Communication Unit, UWE, Bristol. Available at: http://ec.europa.eu/science-environment-policy.

Uraba S, Ebihara A, Komatsu K, Ohbayashi N, Okiji T. Ability of cone-beam computed tomography to detect periapical lesions that were not detected by periapical radiography: a retrospective assessment according to tooth group. J Endod. 2016;42(8):1186-90.

Ustun Y, Aslan T, Sekerci AE, Sagsen B. Evaluation of the reliability of conebeam computed tomography scanning and electronic apex locator measurements in working length determination of teeth with large periapical lesions. J Endod. 2016;42(9):1334-7.

Wanderley VA, Freitas DQ, Haiter-Neto F, Oliveira ML. Influence of tooth orientation on the detection of vertical root fracture in cone-beam computed tomography. J Endod. 2018;44(7):1168-72.

Wu TH, Lin WC, Chen WK, Chang YC, Hwang JJ. Predicting cancer risks from dental computed tomography. J Dent Res. 2015;94(1):27-35.

Yeh JK, Chen CH. Estimated radiation risk of cancer from dental cone-beam computed tomography imaging in orthodontics patients. BMC Oral Health 2018;18(1):131. 